\title{
GLACIOLOGICAL MODELLING OF THE LATE CENOZOIC EAST ANTARCTIC ICE SHEET: STABILITY OR DYNAMISM?
}

\author{
BY \\ PHILIPPE HUYBRECHTS

\begin{abstract}
Alfred-Wegener-Institut für Polar- und Meeresforschung, Germany
\end{abstract} \\ and Geografisch Instituut, Vrije Universiteit Brussel, Belgium
}

Huybrechts, Philippe, 1993: Glaciological modelling of the Late Cenozoic East Antarctic ice sheet: stability or dynamism? Geogr. Ann. 75 A (4): 221-238.

\begin{abstract}
On the basis of geological arguments, two widely different hypotheses have been proposed for the lateTertiary glacial history of East Antarctica. These invoke icesheet reconstructions ranging from severe glaciation completely burying the Transantarctic Mountains to a situation, in which an unstable East Antarctic Ice Sheet repeatedly collapses to produce ice-free conditions over interior basins. Experiments were performed with a $3-\mathrm{D}$ model of the Antarctic Ice Sheet to determine the ice sheet geometries to be expected under various kinds of climatic conditions and the physical mechanisms that may be involved. The results support the concept of a stable East Antarctic Ice Sheet with respect to a climatic warming, and point to the glaciological difficulties involved to explain an ice-free corridor over the Pensacola and Wilkes subglacial basins. The latter event is a crucial element in the "waxing and waning ice sheet hypothesis" and would require a temperature rise of between 17 and $20 \mathrm{~K}$ above present levels. For a temperature rise of less than $5 \mathrm{~K}$, the model actually predicts a larger Antarctic Ice Sheet than today as a result of increased snowfall, whereas the West Antarctic Ice Sheet was found not to survive temperatures 8 $10 \mathrm{~K}$ above present values. Furthermore, basal temperature conditions in these experiments point to the difficulties involved in raising the ice-sheet base to the pressure melting point over the large areas necessary to consider the possibility of sliding instability. A further sensitivity study in terms of topographical and climatic boundary conditions showed that even with a flat bedrock and mass-balance parameters stretched to their limits, the ice sheet would still need a temperature rise of the order of $+15 \mathrm{~K}$ to melt down entirely. Based on these findings, it appears difficult to reconcile a highly variable East Antarctic Ice Sheet with the modest warmings recorded in, for instance, the deep sea records for the late Neogene.
\end{abstract}

\section{Introduction}

The nature and extent of Antarctic glaciation during the late Tertiary is a subject of much debate. Two contrasting views exist, involving widely different ice sheet geometries (Fig. 1). The long-standing view is that local glaciers and ice caps originally formed on the highlands of the East Antarctic cra- ton around the Eocene/Oligocene boundary at $37.5 \mathrm{Ma}$, and subsequently slowly expanded and merged to form a major East Antarctic Ice Sheet between 14 and $11 \mathrm{Ma}$. Since then, it is believed that this ice sheet remained a semi-permanent feature exhibiting some changes in volume (Kennett, 1977; Denton et al. 1991). If anything, the ice sheet was larger than today, with at least one phase during the Miocene in which the Transantarctic Mountains were overridden by an ice sheet of considerably larger volume than anything recorded since (Denton et al. 1984). This stabilist view not only results from the interpretation of the marine sediment record of the Southern Ocean and oxygen isotope ratios of planktonic foraminifera (Kennett, 1982), but is also supported by recent geomorphological and geological work in the Dry Valleys region, pointing to prolonged cold-desert conditions for much of the last 10 million years (Sugden, 1992; Marchant et al. 1993). The marine West Antarctic Ice Sheet, on the other hand, grounded on a bed below sea level, probably matured later between 10 and $5 \mathrm{Ma}$, and has been responsible for the bulk of the variability of the Antarctic Ice Sheet since then (Kennett, 1982).

This classic view of a quasi-permanent East Antarctic Ice Sheet since at least the mid-Miocene has recently been challenged by the discovery of reworked marine diatoms in the Sirius Group deposits in the Transantarctic Mountains. In order to explain their occurrence, the "waxing and waning ice sheet hypothesis' proposes a series of events involving the repeated opening of a seaway across the subglacial Wilkes and Pensacola basins (Fig. 1), in which marine diatom deposition could take place, followed by an expanding ice sheet, which subsequently overrode the Transantarctic Mountains and transported the diatoms to their present locations (Webb et al. 1984; Webb and Harwood, 1991). Based on the ages of the youngest diatoms 

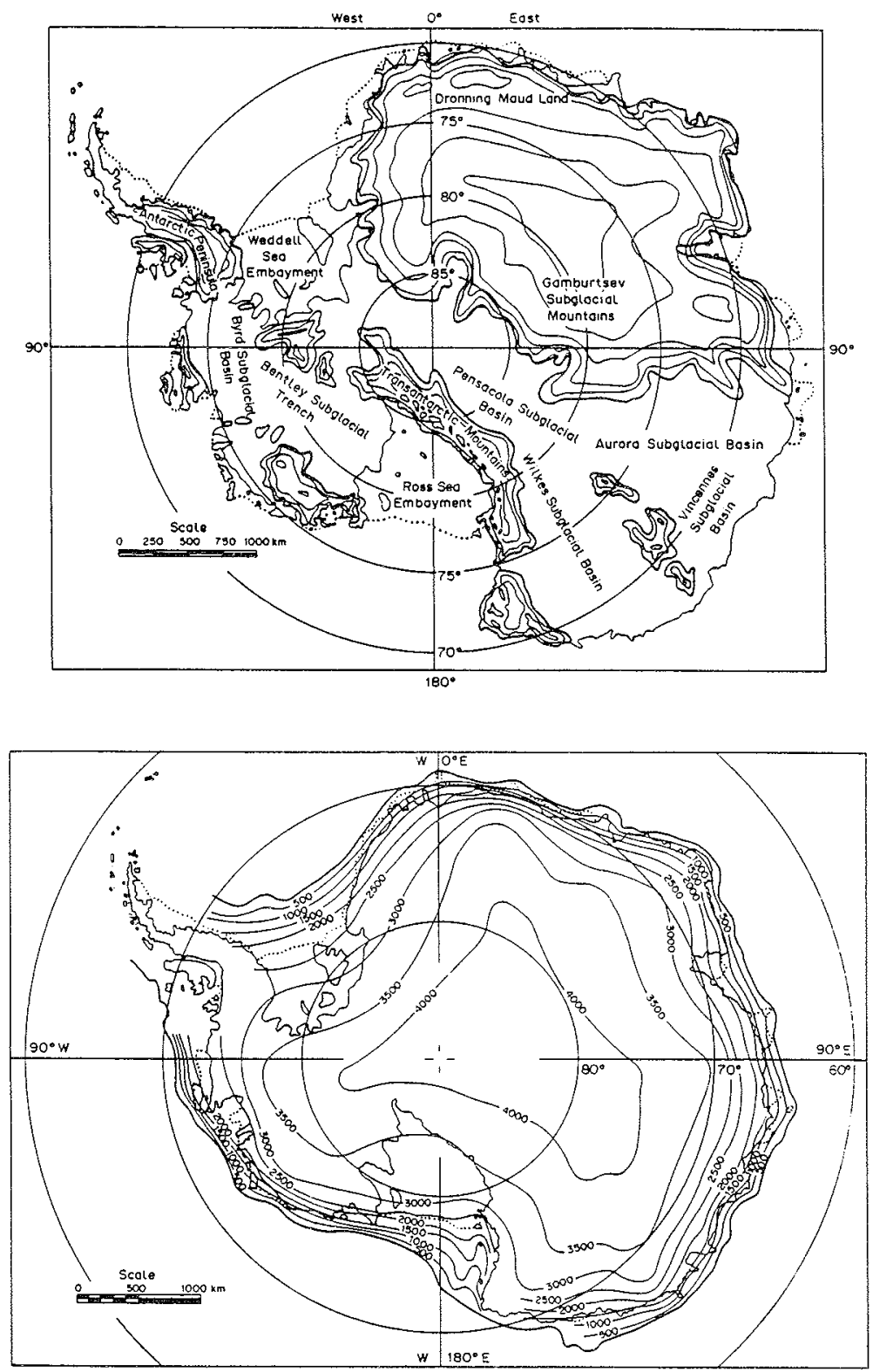

Fig. 1. Extreme glaciation phases invoked to explain late Tertiary geological features in the Transantarctic Mountains. Above: possible geometry of Antarctica during an extcnsive deglaciation phase as put forward by the 'waxing and waning' ice sheet hypothesis (from Denton, 1985). Below: the hypothetical 'giant ice sheet' needed to override the Transantarctic Mountains during a maximum phase (from Dentonetal. 1984).

in the Sirius Group (Harwood, 1986; Barrett et al. 1992), the latest episode of a largely ice-free continent would have occurred as recently as the mid to late Pliocene around $3 \mathrm{Ma}$. This highly unstable behaviour has led to the suggestion that the East Antarctic Ice Sheet is very sensitive to global warming and could again largely disappear in the relatively near future if global temperatures in- creased by a few degrees. The implications would be far-reaching: if melted, the East Antarctic Ice Sheet would raise world-wide sea-levels by an estimated $60 \mathrm{~m}$.

When discussing these hypotheses, it is useful to first put the present Antarctic Ice Sheet in perspective and discuss its response modes to environmental change. At present, air temperatures are so low 
that surface melting and runoff are virtually absent. As a consequence, the surface mass-balance is positive almost everywhere and the ice sheet loses its mass primarily by calving of icebergs and some melting below ice shelves. Under these conditions, the extent of the ice sheet is limited mainly by the depth of the surrounding ocean. A change of eustatic sea level, for instance, would cause an immediate shift of the grounding line in order to preserve hydrostatic equilibrium. This locates the greatest potential for change in the West Antarctic Ice Sheet, where the bedrock lies far below sea level; the ice sheet does not occupy the entire continental shelf; and the area between the current grounding line and the edge of the continental platform is rather flat.

The East Antarctic Ice Sheet, on the other hand, at present occupies almost the entire available land-base. Its grounding line is close to the steep continental slope, leaving little room for major seaward changes in its extent. For the ice sheet to recede from the continental platform, the climate would first have to warm enough to produce a peripheral ablation zone of sufficient width. Under the current cold climate, where little melting occurs and precipitation amounts are $\mathrm{i}^{-}$ mited by the low air temperatures, the Antarctic Ice Sheet is still located in a region where mass balance will increase with temperature because of increased precipitation (Huybrechts and Oerlemans, 1990). This implies that the smaller East Antarctic Ice Sheet with the lower surface elevations is more likely to be associated with a colder rather than a slightly warmer climate compared to today.

The following discussion concentrates on climates warmer than today. An investigation is made of ice sheet geometries resulting from various temperature increases, the physical mechanisms involved and the associated time scales for growth and decay. A three-dimensional thermomechanical model is applied to the entire Antarctic Ice Sheet in connection with simple mass-balance considerations. Sections 2 and 3 describe the ice sheet model and the boundary conditions needed to define the ice sheet. Results are presented in section 4 . Section 5 deals with a sensitivity study in terms of bedrock topography and mass balance conditions, and is followed by a discussion on the implications for the late-Neogene glacial history of Antarctica.

\section{The Ice Sheet Model}

The ice sheet model discussed below treats ice flow and its thermodynamics by solving the full set of coupled thermomechanical equations on a fine mesh in three dimensions. It is time-dependent and includes the response of the underlying bedrock to a changing ice load. There is free interaction between climatic input and ice thickness, so that the entire geometry is internally generated. Except for the omission of a coupled ice shelf, the model is basically similar to the one used to study the Antarctic Ice Sheet on glacial-interglacial and greenhouse warming time scales (Huybrechts, 1992). A full account of the mathematical equations and numerical techniques governing the model is given by Huybrechts (1992).

In short, the basic equations that are solved in the model are conservation equations for mass and heat:

$$
\begin{aligned}
& \frac{\partial \mathrm{H}}{\partial \mathrm{t}}=-\nabla \cdot(\stackrel{\overrightarrow{\mathrm{v}} \mathrm{H})}{ }+\mathrm{M} \\
& \frac{\partial \mathrm{T}}{\partial \mathrm{t}}=\frac{\mathrm{k}}{\rho \mathrm{c}_{\mathrm{p}}} \nabla^{2} \mathrm{~T}-\overrightarrow{\mathrm{V}} \cdot \nabla \mathrm{T}+\frac{\Phi}{\rho c_{p}}
\end{aligned}
$$

where $H$ is ice thickness, $\overrightarrow{\bar{v}}$ the depth-averaged horizontal velocity field, $M$ the mass balance and $\mathrm{t}$ is time. The thermodynamic equation accounts for vertical heat conduction, three-dimensional advection, and heat generation by internal deformation. Here, $\mathrm{T}$ is temperature, $\rho$ is ice density $\left(910 \mathrm{kgm}^{-3}\right), \vec{V}$ is three-dimensional ice velocity, $\phi$ is layer heating, and $\mathrm{k}$ and $c_{\mathrm{p}}$ are temperature dependent thermal conductivity and specific heat capacity, respectively. Boundary conditions are the mean annual air temperature at the upper surface and a temperature gradient at the lower surface incorporating the effects of geothermal heating and heat dissipation by sliding. A geothermal heat flux of $1.3 \mathrm{HFU}=54.6 \mathrm{~mW} / \mathrm{m}^{2}$ was taken, which is usually considered as an average value for the entire Antarctic continent.

Only grounded ice flow is taken into account. The usual assumptions are used (Paterson, 1981): ice deformation is assumed to result from shearing in horizontal planes and longitudinal deviatoric stresses are disregarded. Expressions for the horizontal velocity components can be derived by substituting equations for the shear stress distribution $\tau(\mathrm{z})$ in the flow law, which is of 'Glen-type' with exponent $n=3$, and integrating the result with respect to the vertical. This yields: 
$\tau(\mathrm{z})=-\rho g(\mathrm{H}+\mathrm{h}-\mathrm{z}) \nabla(\mathrm{H}+\mathrm{h})$

$$
\begin{aligned}
& \overrightarrow{\mathrm{v}}(\mathrm{z})-\overrightarrow{\mathrm{v}}(\mathrm{h})=-2(\rho \mathrm{g})^{3}[\nabla(\mathrm{H}+\mathrm{h}) \cdot \nabla(\mathrm{H}+\mathrm{h})] \\
& \nabla(\mathrm{H}+\mathrm{h}) \int_{\mathrm{h}}^{\mathrm{z}} \mathrm{A}\left(\mathrm{T}^{*}\right)(\mathrm{H}+\mathrm{h}-\mathrm{z})^{3} \mathrm{dz}
\end{aligned}
$$

where $\bar{v}(h)$ is the basal boundary condition on velocity, $h$ is bed elevation and $\mathrm{A}\left(\mathrm{T}^{*}\right)$ expresses the temperature dependence of the flow-law parameter, which is given by an Arrhenius equation. $\mathrm{z}$ is the vertical and $\mathrm{g}$ is gravity.

Basal sliding takes places when the basal temperature is within $1 \mathrm{~K}$ of the pressure melting point, and is of Weertman-type:

$$
\vec{v}(h)=-A_{S}(\rho g)^{3} H^{2}[\nabla(H+h) . \nabla(H+h)] \nabla(H+h)
$$

where $A_{s}=1.810^{-11} \mathrm{~N}^{-3} \mathrm{yr}^{-1} \mathrm{~m}^{7}$.

A second integration with respect to the vertical yields the mean horizontal ice mass flux:

$$
\overrightarrow{\bar{v}} \mathrm{H}=\int_{h}^{\mathrm{H}+\mathrm{h}} \overrightarrow{\mathrm{v}}(\mathrm{z}) \mathrm{dz}
$$

Vertical motion $w(z)$, as a result of accumulation and vertical strain, is calculated from the incompressibility condition:

$$
w(z)-w(h)=-\int_{h}^{z} \nabla \cdot \vec{v}(z) d z
$$

Finally, bed adjustments are calculated in a simple way. The steady state deflection is given by local isostatic equilibrium, whereas the time-dependent response is modelled as a damped return with a characteristic time scale of $\Theta$ equal to 3000 years:

$$
\begin{aligned}
& \frac{\partial h}{\partial t}=-\frac{1}{\Theta}\left[h-h_{0}+d\right] \\
& d=\frac{\rho}{\rho_{m}} H
\end{aligned}
$$

where $\rho_{\mathrm{m}}$ is mantle density $\left(3300 \mathrm{kgm}^{-3}\right), \mathrm{d}$ is lithospheric deflection and $h_{0}$ is the undisturbed bed elevation when the ice sheet is removed and isostatic rebound is complete.

All equations are solved on a numerical grid with the finite-difference method. The grid point distance is $40 \mathrm{~km}$. With 11 layers in the vertical, with closer spacing near the bedrock surface where the shearing concentrates, this leads to a domain of somewhat over 200000 grid points. Time steps are 10 years. The model is implemented on a CRAY 2-S. On this machine, it takes about 1 hour of CPU time for a 100000 year integration.

The major difference compared to a previous version of this model (Huybrechts, 1990) is that an explicit calculation of ice-shelf flow and grounding-line dynamics was not made. Instead, the present grounding-line position was taken as a constraint, beyond which all ice is lost to the ocean. Expansion of grounded ice over terrain below sea level is thus still possible, but is entirely controlled by the surface mass-balance and the ability of the ice sheet to extend down to sea level. In effect, all ice is treated as grounded ice irrespective of the bed elevation, with the limitation that it cannot expand beyond its present limits. This approach to modelling the marine boundary is not considered a serious problem, because the ice sheet will retreat onto the East Antarctic continent in a warmer climate and will no longer interact with the ocean directly. As is the case in Greenland today, any ice that is still able to reach the ocean will then disappear at the coast by calving. The greenhouse warming experiments reported in Huybrechts and Oerlemans (1990) did not show any appreciable seaward movement of the grounding-line, even when overall volume grew in the case of limited warming.

\section{Boundary Conditions}

The primary inputs to the model are bed elevation and mass balance at any time and place in the model domain. These entirely determine the ice sheet geometry.

\section{Bedrock Topography}

The dataset for bedrock topography originates from the Drewry (1983) map folio series, and was slightly smoothed to make it suitable for the model. A contoured representation of these data is shown in Fig. 2. Clearly, substantial parts of the bedrock are at present far beneath sea level. Even after the removal of the ice sheet and the sub- 


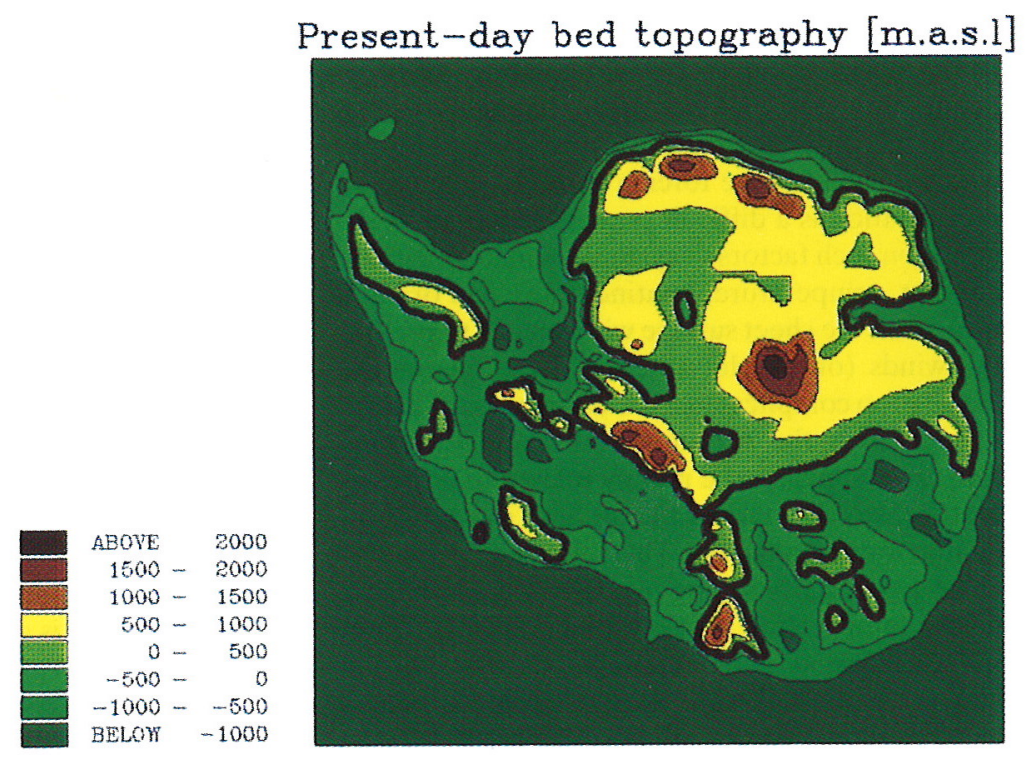

Fig. 2. The current bedrock topography of Antarctica (above) and the rock surface that would result after the removal of the present ice load and subsequent isostatic rebound (below). Contoured values (in $m$ above contemporary sea level) have undergone light smoothing, the thick line is for the zero-meter contour. Data were digitized from the Drewry map folio series, sheet 3 (1983).

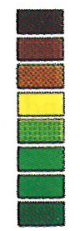

\section{Bed topography after isostatic rebound}

sequent isostatic rebound, this remains the case in West Antarctica, where only a few isolated islands rise above the ocean surface and water depths are still as much as 1000 metres or more. By contrast, if the East Antarctic Ice Sheet were to be removed and full isostatic recovery were to take place, practically all of the bed would rise above sea level. This also applies to the Wilkes and Pensacola basins, which are at present near or below sea level,

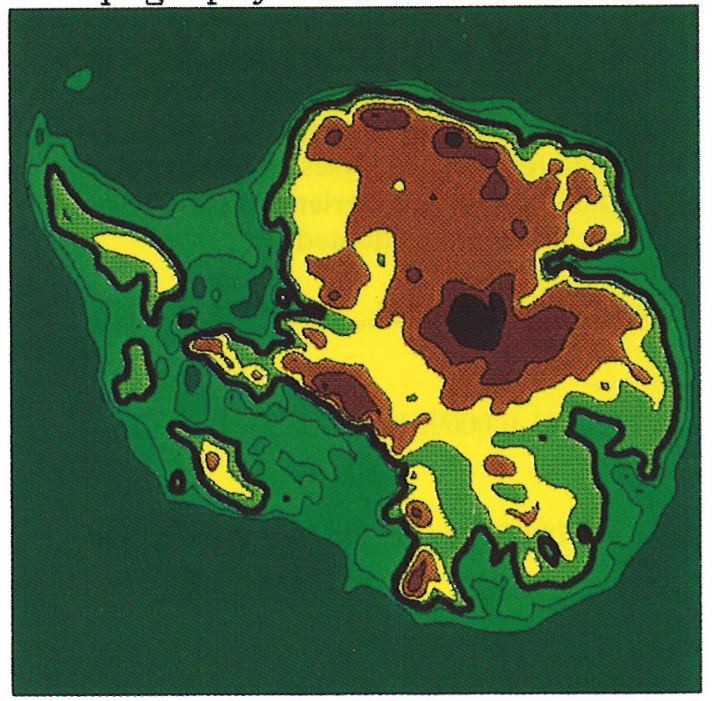

but would rise to between 500 and $1000 \mathrm{~m}$ above sea level after removal of the ice sheet. This makes an open seaway across these basins improbable unless the bed had an entirely different structure. This is definitely a weak point in the waxing and waning hypothesis, and has so far not been adequately addressed. 


\section{The Mass Balance}

In the model, the mass-balance components of accumulation rate and runoff are calculated separately and parameterised in terms of temperature, which is the ultimate forcing variable. In general, precipitation is a difficult process to model. It depends on such factors as cyclonic activity, moisture content, temperature, continentality and orientation of the ice sheet surface with respect to prevailing winds (orographic effect). These factors are usually too complicated to be used in a parameterisation. Over the Antarctic, however, accumulation rates appear to be mainly related to air temperature, which controls the amount of vapour available for precipitation. This relationship appears to be particuiarly strong over the inland plateau, where temperature alone explains over $85 \%$ of the variation of the accumulation rate (Fortuin and Oerlemans, 1990). Results from the Vostok ice-core show that this relation also holds during a glacial cycle, and it is believed to have continental validity (Jouzel et al. 1989).

The parameterisation developed for this study is based on the premise that temperature remains the main controlling factor for precipitation in earlier Antarctic climates, which may have had widely different geographies. Using data from Orvig (1970) and following analyses by Giovinetto et al. (1990) and Fortuin and Oerlemans (1990), the following relations were adopted:

$\mathrm{TMA}=34.46-0.00914 \mathrm{H}_{\text {sur }}-0.68775 \mathrm{Lat}+\mathrm{T}_{\text {for }}$

TMS $=16.81-0.00692 \mathrm{H}_{\text {sur }}-0.27937 \mathrm{Lat}+\mathrm{T}_{\text {for }}$

$$
\mathrm{ACC}=0.78+2.525 \times 10^{-2} \mathrm{TMA}+2.225 \times 10^{-4} \mathrm{TMA}^{2}
$$

where TMA $\left[{ }^{\circ} \mathrm{C}\right]$ is the mean annual surface air temperature, $\mathrm{H}_{\mathrm{sur}}$ is surface elevation in metres above sea level, Lat is latitude in ${ }^{\circ} \mathrm{S}$ and $\mathrm{T}_{\text {for }}$ is the applied temperature change with respect to present conditions. ACC $[\mathrm{m} / \mathrm{y}$ ice equivalent $]$ is the parameterised accumulation rate, and gives a reasonable fit to the presently observed snowfall distribution (Fig. 3, p. 228). It ranges from as little as $5 \mathrm{~cm} /$ year for a minimum air temperature of $-56^{\circ} \mathrm{C}$ to around $0.5 \mathrm{~m} /$ year for a mean annual temperature of $-12^{\circ} \mathrm{C}$. Somewhat larger discrepancies with respect to the observations are found on the Antarctic Peninsula and along parts of West Antarctica. This is due to a more pronounced cyclonic activity, which is not accounted for by the adopted relation. Fig. 4 (p. 228) shows how the temperature parameterisation works for present conditions. Mean annual temperatures are then around $-15^{\circ} \mathrm{C}$ along most of the East Antarctic coast and down to $-60^{\circ} \mathrm{C}$ over the plateau, generally in good agreement with observations.

TMS is the summer temperature needed to construct the yearly temperature march in the ablation model, which is based on the degree-day method. Braithwaite and Olesen (1989) have shown that there is a high correlation between the number of positive degree days and melt rates at west Greenland ice-margin locations. The model adopted to estimate the number of positive degree-days (PDDs) accounts for the daily cycle and for random temperature variations from the regular long-term annual cycle by using a statistic, that is normally distributed and centred on the curve of the mean daily temperature TD:

$$
\begin{aligned}
& \mathrm{PDD}=\frac{1}{\sigma \sqrt{2 \pi}} \int_{0}^{\mathrm{A}} \\
& \int_{0}^{\mathrm{TD}+2.5 \sigma} \mathrm{T} \exp \left[\frac{-(\mathrm{T}-\mathrm{TD})^{2}}{2 \sigma^{2}}\right] \mathrm{dT} d \mathrm{dt}
\end{aligned}
$$

where $\sigma$ is $5 \mathrm{~K}$ and TD is defined as a cosine with mean of TMA and an amplitude of TMA-TMS (Reeh, 1989). A equals one year.

The calculated annual number of PDDs represents a melt potential, which is used to melt snow and ice with degree-day factors of $0.003 \mathrm{my}^{-1}$ /PDD and $0.008 \mathrm{my}^{-1} / \mathrm{PDD}$, respectively. The higher value for ice is essentially related to a lower albedo for bare ice as compared to snow. Additional features such as superimposed ice formation and the fraction of precipitation falling as rain, which are of importance for the present-day ice

Figs 3 and 4, see p. 228. For technical reasons Figures 3,4 and 7 are out of sequence. 


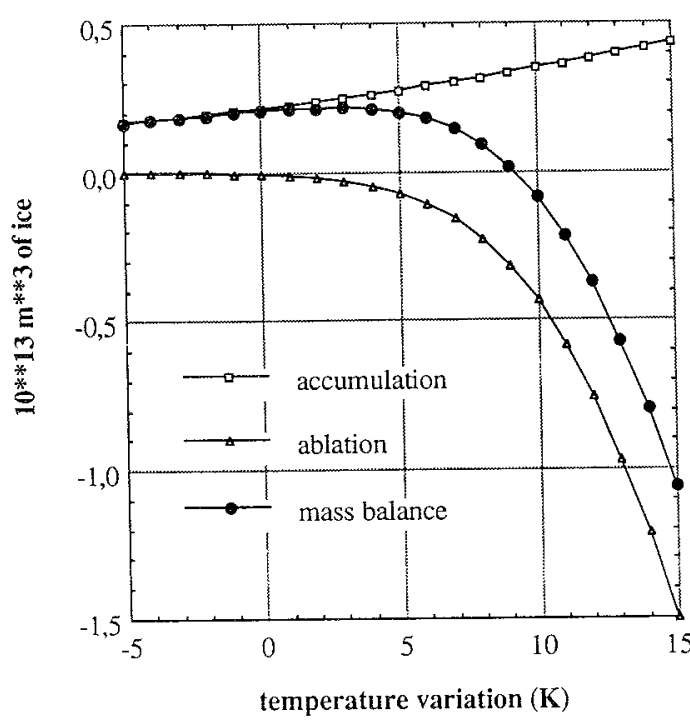

Fig. 5. Dependence of Antarctic mass-balance components on temperature relative to the present. For a warming below $5.0^{\circ} \mathrm{C}$, the mass balance would be larger than today. Values are integrated over the entire grounded ice sheet for its present geometry.

sheets in Greenland and the Canadian Arctic, have been disregarded. This is simply because uncertainties in the other climatic boundary conditions would not justify such a degree of sophistication. This method of determining glacier runoff is similar to the procedure adopted in Huybrechts et al. (1991), where it was satisfactorily employed to determine ablation rates on the Greenland Ice Sheet. Greenland can be considered as the modern analogue for an (East-) Antarctic Ice Sheet in a climate warmer by 10 to $15 \mathrm{~K}$ in the annual mean.

It is instructive to see how the total ice budget gained (or lost) at the surface depends on temperature. Fig. 5 displays the surface mass-balance components integrated over the entire grounded ice sheet for its present geometry. It shows how accumulation rates increase in a warming climate, so that a surface temperature increase of $10 \mathrm{~K}$ corresponds roughly to a $60 \%$ increase of the accumulation rate. Runoff is virtually absent for presentday conditions, but is seen to increase progressively with temperature. As a result, for a moderate warming of up to $5 \mathrm{~K}$, the mass balance will be even higher than today because the increase in accumulation outweighs the increase in runoff. When mass balance is zero, the ice sheet is in equilibrium. The present ice sheet has a positive surface mass balance, meaning that more ice is gained by accumulation than lost by ablation. The implication is that the ice sheet must be losing mass by another mechanism (calving) if it is to retain a steady state. The mass balance will become negative for a temperature rise of more than $9 \mathrm{~K}$. This does not mean that the Antarctic Ice Sheet will disappear for temperature rises larger than 9K. In general, the ice sheet will shrink and try to reorganise its height-elevation distribution so as to make the accumulation area larger at the expense of the ablation area. The Greenland Ice Sheet has at present a fifty-fifty ratio between mass loss by calving and by runoff (Huybrechts et al. 1991). On the mass-balance curve displayed in Figure 5, this would correspond to a temperature rise of around $7 \mathrm{~K}$.

\section{The Modelling Results}

Ice Sheet Geometries

A series of experiments was conducted in which the present ice sheet was taken as an initial condition and temperatures were progressively raised. The initial condition was obtained by starting with the observed ice sheet and running the model to equilibrium with zero temperature forcing. During this process, the final ice thickness distribution was generally within 100 metres of the observations, which is certainly acceptable. For each new value of the temperature perturbation, the evolution of the ice sheet was computed for 100000 years, which was sufficient to reach an approximate steady state.

Fig. 6 shows the resulting steady-state ice sheet geometries for temperature changes of between 5 and $20 \mathrm{~K}$ above present levels. For a temperature increase of up to $5 \mathrm{~K}$, the ice sheet geometry is rather stable. There is a slight retreat of ice along the northernmost tip of the Antarctic Peninsula and elevations tend to rise a little over the continental interior, but the overall form of the ice sheet exhibits only minor changes. This is because melting at the margin is not yet of sufficient strength to form an ablation arca along the coast of any significance. The formation of such an ablation area, in which runoff exceeds accumulation on a yearly basis, is a necessary pre-condition for the ice sheet to recede over its continental base. In addition, in the central areas the thickening effect of increased accumulation rates is partly counteracted by thinning associated with warmer and softer ice. This is very similar to the behaviour reported for the Ant- 


\section{P. HUYBRECHTS}

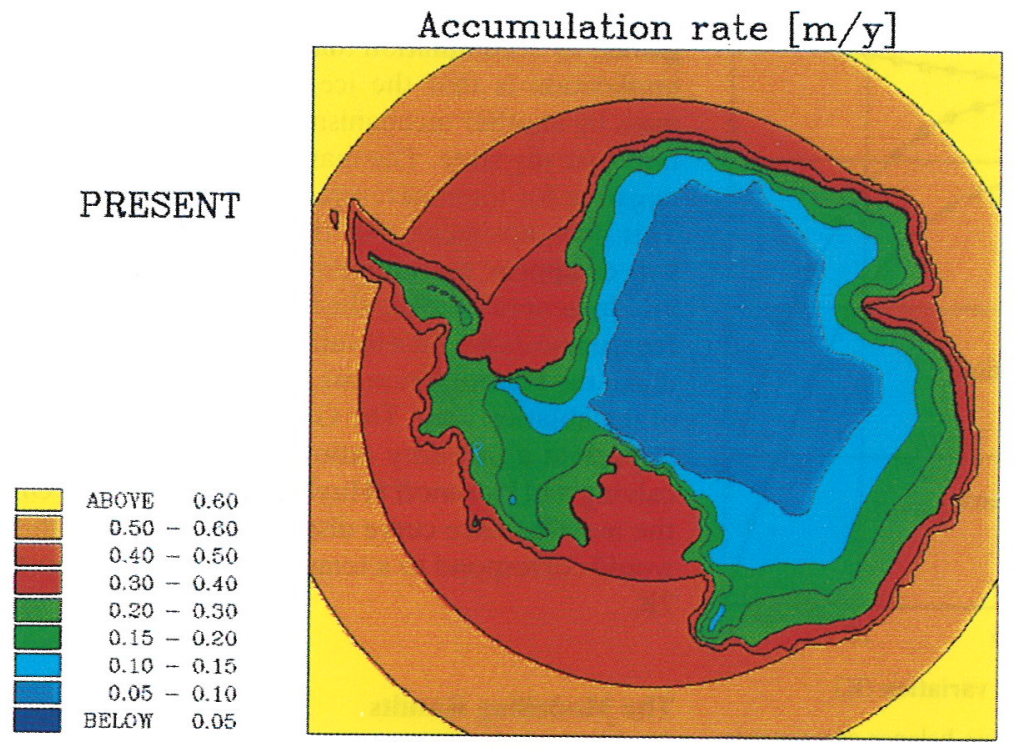

Fig. 3. The parameterised accumulation rate for the presentday ice sheet. Values are in $\mathrm{m} / \mathrm{y}$ ice equivalent.
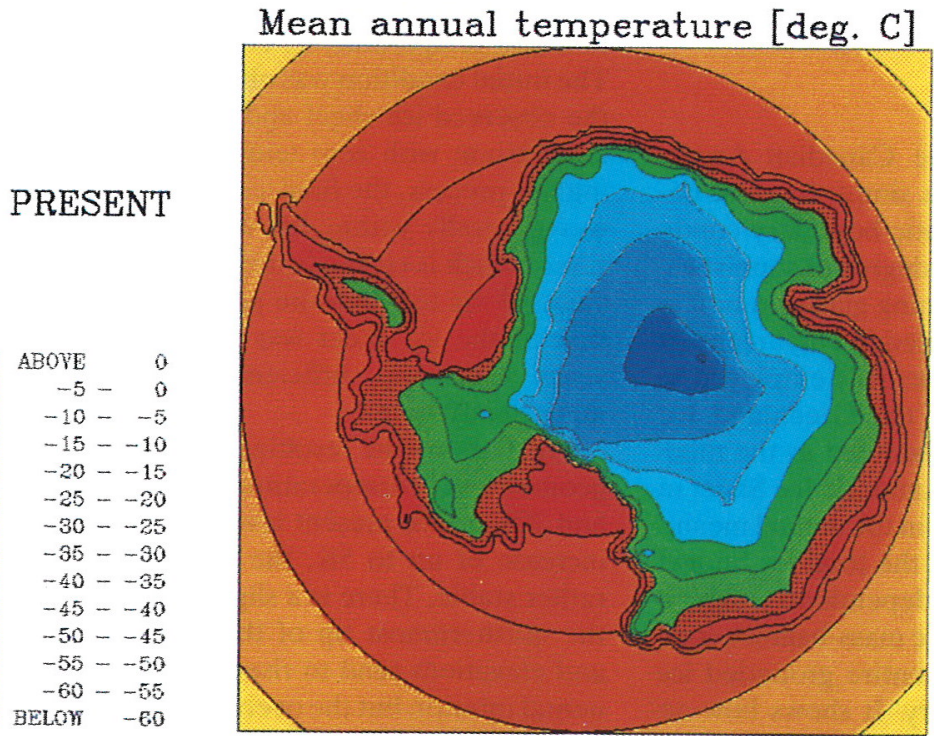

Fig. 4. Mean annual surface temperature $\left[\right.$ in $^{\circ} \mathrm{C}$ ] for the present-day ice sheet according to the parameterisation adopted for this paper. This is also the upper boundary condition for the temperature calculations within the ice sheet.

arctic Ice Sheet during a glacial-interglacial contrast, where eustatic sea-level change rather than climatic change was found to be the most decisive factor controlling fluctuations of the ice sheet (Huybrechts, 1990).

A first threshold is crossed for a warming in the range of 8 to $10 \mathrm{~K}$. For a temperature rise of $+9 \mathrm{~K}$, most of the ice cover over the Antarctic Peninsula has retreated to the high central mountain ridge and the Peninsula Ice Cap has become separated from the West Antarctic Ice Sheet. This leads to an open seaway between Palmer Land and Ellsworth Land. For a warming of between 9 and $10 \mathrm{~K}$, the mass balance over most of West Antarctica has become sufficiently negative at sea level so that grounded ice is no longer able to produce a flux across the grounding line and feed an ice shelf. This starts a chain of reactions that ultimately results in 


\section{+15 deg. C}

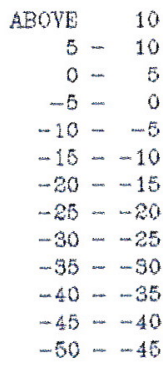

Fig. 7. Climatic boundary conditions for the ice sheet simulated for a temperature warming of $+15 \mathrm{~K}$. The thick black line in the lower graph is the equilibrium line. The magnitudes of the mass balance and the surface temperature are comparable to those observed on Greenland today.

\section{+15 deg. C}

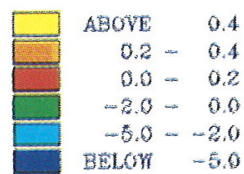

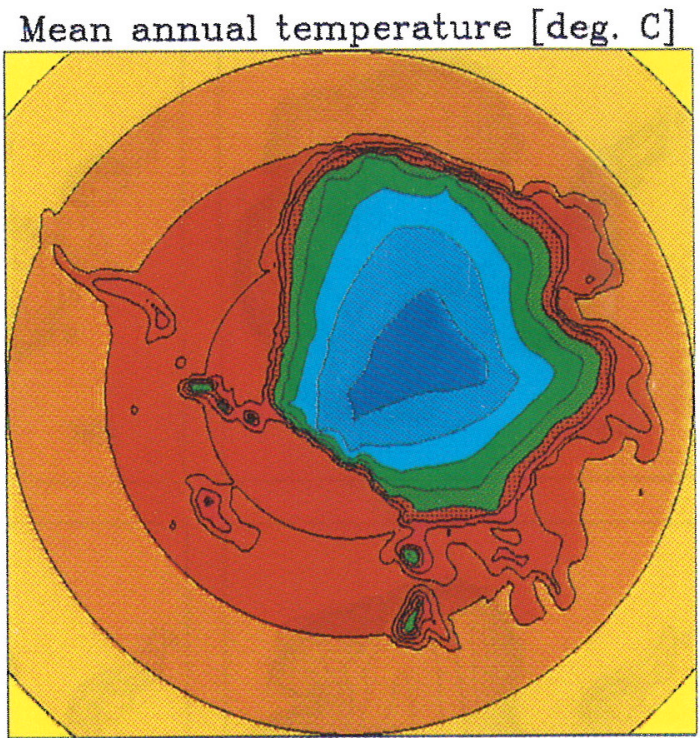

Mass balance $[\mathrm{m} / \mathrm{y}]$

the almost total destruction of the marine portions of the West Antarctic Ice Sheet. In these experiments, the mechanism called upon for ice sheet decay does not involve direct interaction with the ocean, but is due to the height-mass balance feedback: melting of the West Antarctic Ice Sheet at its margin leads to a shrinking base and lower elevations, which then further enlarges the ablation area and so on. For a warming of around $10 \mathrm{~K}$, the ice sheet also starts to retreat from the continental margin in East Antarctica and ice shelves cease to exist

As shown on the bottom maps in Figure 6, the Antarctic Ice Sheet starts to retreat more seriously for temperature rises above $15 \mathrm{~K}$, when local ice caps appear in Victoria Land and the Ellsworth Mountains that are disconnected from the main ice sheet. A second threshold, now associated with 


\section{P. HUYBRECHTS}
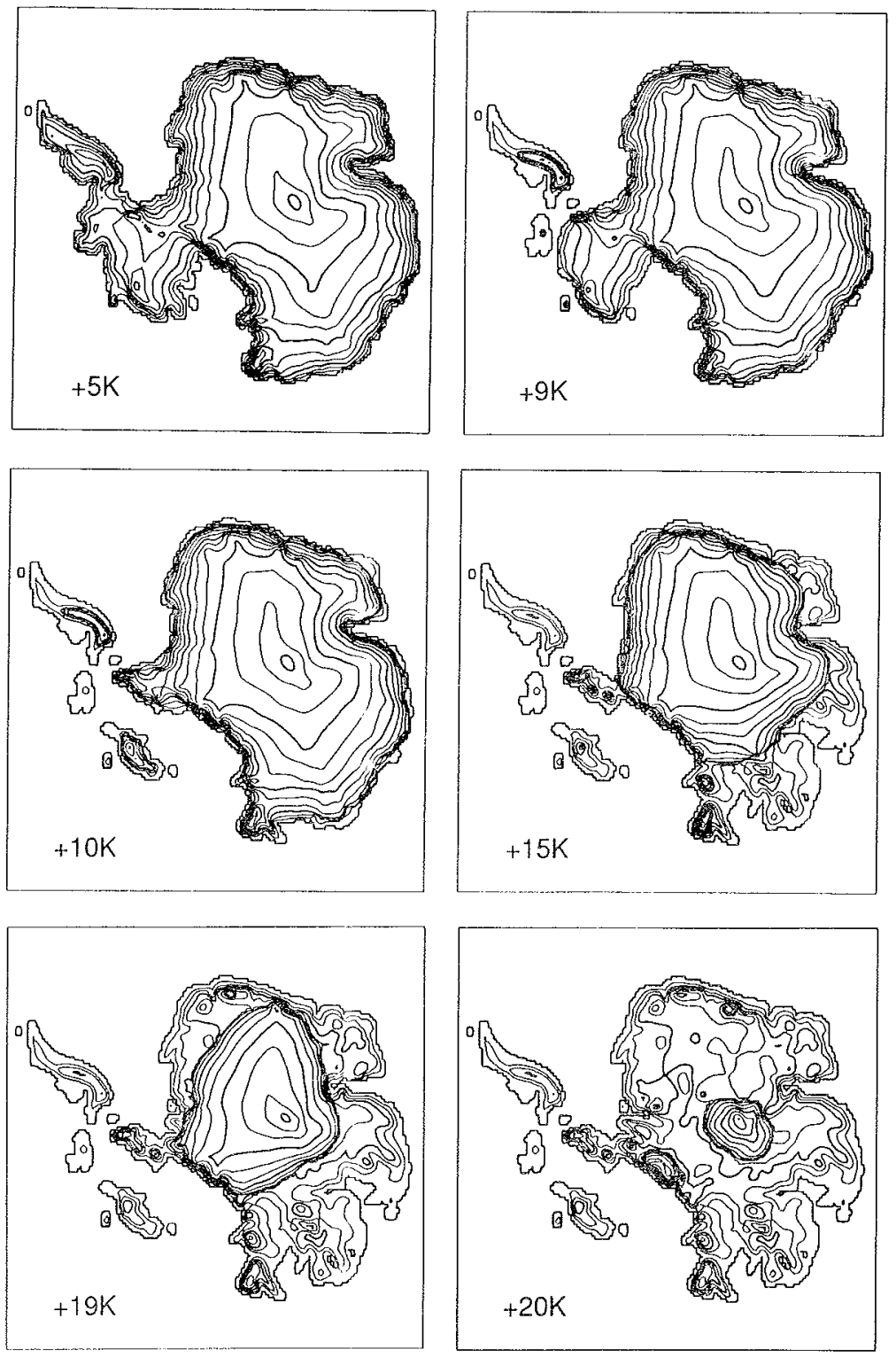

Fig. 6. Steady-state ice-sheet geometries for the temperature perturbations above present levels as indicated. Isolines are for surface elevation. Contour interval is $333 \mathrm{~m}$, the thick lines are every $1000 \mathrm{~m}$.

the East Antarctic Ice Sheet, is crossed for temperatures in the range of +19 to $+20 \mathrm{~K}$. At this stage, the East Antarctic Ice Sheet has basically disintegrated into two ice caps situated on top of the Transantarctic and the Gamburtsev Mountains. A small ice cap also survives in the Sør Rondane Mountains, which acts as a third inception area. The presence of these mountains explains why the East Antarctic Ice Sheet is able to resist a much larger warming than the West Antarctic Ice Sheet for a similar latitude, because these mountains enable the ice sheet to retreat to higher ground. It is also interesting to note that an ice-free corridor centred over the Pensacola subglacial basin, where marine sedimentation could take place as invoked by the waxing and waning hypothesis, is only produced when the ice sheet as a whole has almost entirely disappeared. 
Fig. 7 (p. 229) shows the climatic conditions associated with the ice sheet simulated for a temperature rise of $15 \mathrm{~K}$. Even then, mean annual surface temperatures are still below $-40^{\circ} \mathrm{C}$ over the central parts, and mass balance values range from $30 \mathrm{~cm}$ per year to negative values of minus 5 metres per year. These are of the same order of magnitude as those observed on Greenland today and demonstrate the difficulty of eliminating the ice sheet.

It is also interesting to note that in spite of the increased accumulation rates, surface elevations over East Antarctica and the Transantarctic Mountains do not rise much. This is in part due to the warmer and softer ice, but the main reason is the shrinking base because of melting at the margin and subsequent retreat. Though it is not explicitly modeled, higher surface elevations in the Transantarctic Mountains are also unlikely to come from widespread grounding of the West Antarctic Ice Sheet. Even if the ice sheet expands to the edge of the continental shelf during a Pleistocene glacial maximum, surface levels at the inland side of the Transantarctic Mountains, where they are highest, are not very different from today (Huybrechts, 1990; Denton et al, 1991). This is at odds with the maximum ice sheet reconstruction shown in Fig. 1, which would require a fully expanded West Antarctic Ice Sheet together with substantially larger accumulation rates than those observed during the more recent glacial history. From what is known of Antarctica during the late Quaternary, such conditions exclude one another, making the 'giant ice sheet reconstruction' also difficult to accept for the late Neogene.

\section{Basal Temperature Conditions}

Another important characteristic for ice sheet dynamics is the extent of basal melting, because the presence of liquid water is a necessary prerequisite for enhanced basal motion, whether this occurs as basal sliding at the ice-rock interface or by means of a deforming layer of soft sediments. The resulting distribution of areas at the pressure melting point is displayed on Fig. 8. Interestingly, the present-day pattern of basal melting is quite well conserved and changes in a warmer climate are modest. Though there is some expansion of wet ice, basal melting remains mainly confined to regions with thick ice, whereas the shallower ice covering the Transantarctic and the Gamburtsev Mountains continues to be cold-based, even with a temperature rise of $20 \mathrm{~K}$. This behaviour is the result of two largely counteracting effects: in a warmer climate the surface ice becomes warmer, but on the other hand increased accumulation rates will lead to a more vigorous motion of the ice within the ice sheet, so that more cold ice is advected downwards. As a result, the steady-state surface-to-bottom temperature difference is reduced and the ensuing basal warming is only a fraction of the initial surface warming. The implication for the dynamics of the East Antarctic Ice Sheet is that any instability mechanism invoking widespread basal melting is unlikely to have played a major role in the ice sheet's history.

\section{Ice Volume}

The results of these experiments are best summarized in a solution diagram giving the equilibrium ice volume as a function of the temperature perturbation (Fig. 9). Two sets of model runs are shown, one in which the present ice sheet was used as an initial condition, and one in which the calculations started from the bare bedrock after isostatic rebound. Clearly, there are regions with multiple solutions. For certain values of the temperature perturbation, the final state of the ice sheet depends on whether the ice sheet was initially present or not. This is indicative of hysteresis (Oerlemans, 1981), though its magnitude is not particularly large: the two solutions are separated by $1 \mathrm{~K}$ at most. This type of behaviour is due to the fact that an ice sheet creates its own surface climate, so that when the ice sheet is removed, it needs a colder climate to regrow to the same size. The curve connected by open squares can be understood as the path the ice sheet would follow when it melts; the full squares represent the build up. The region around $+9 \mathrm{~K}$ is linked to the threshold for the West Antarctic Ice Sheet, whereas the region between +16 and $+20 \mathrm{~K}$ is associated with the East Antarctic Ice Sheet.

Furthermore, the Antarctic Ice Sheet is larger than today for a climatic warming of up to $5 \mathrm{~K}$, because the surface mass balance is higher than today. Above this temperature, the increase in

\footnotetext{
Fig. 7, see p. 229.
} 

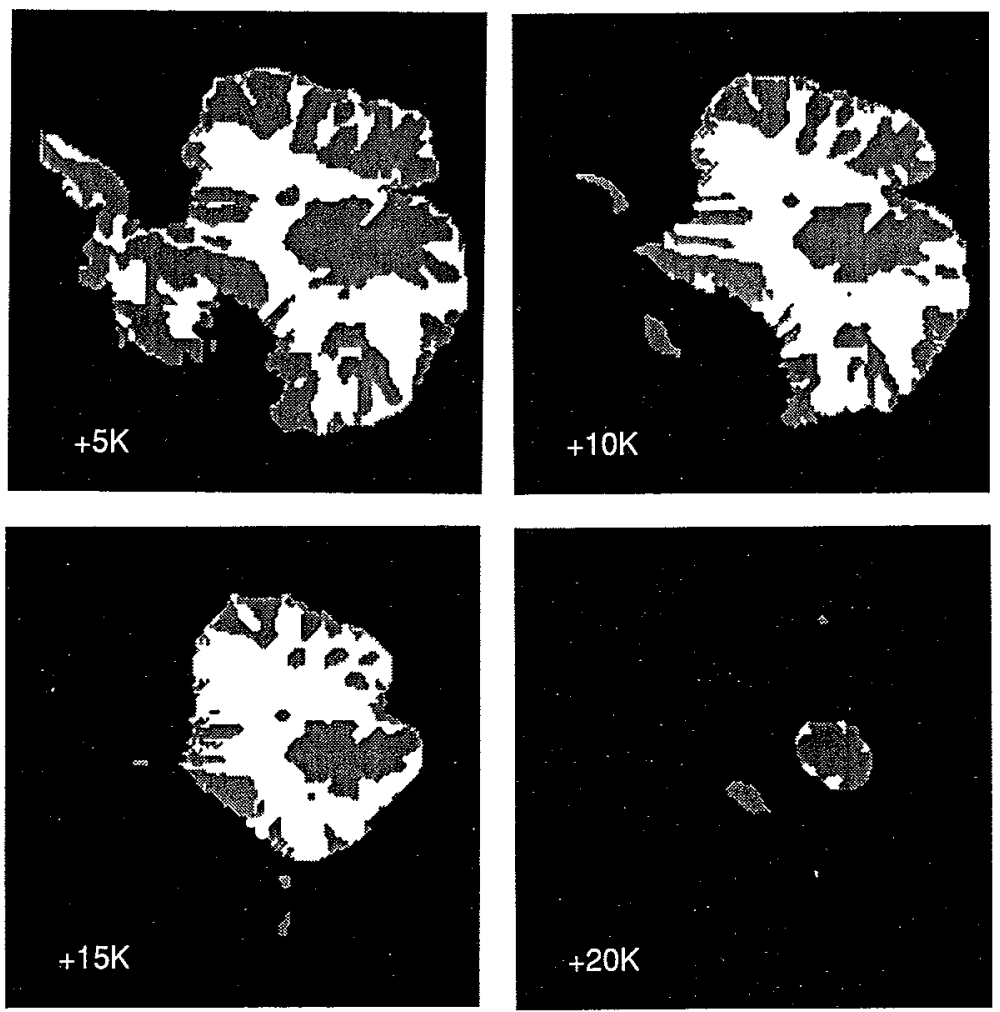

Fig. 8. Basal temperature conditions corresponding to the series of experiments shown in Fig. 6. White areas indicate where the base is at the pressure melting point and basal sliding can occur. These plots demonstrate that mixed wet and cold basal conditions also prevail in warmer climates, much like the situation today.

melting starts to dominate over the increase in accumulation, and an ablation area develops around the coast. The ice sheet disappears completely for a climate more than $25 \mathrm{~K}$ warmer than today. In this case, there are no regions left in the model domain with a positive surface mass balance.

\section{Response Time Scales}

Figs 10 and 11 show the time scales involved to build up or melt down the ice sheets in these experiments. As shown on these graphs, it takes considerably more time to build up an ice sheet than to melt it down. This is because of the different behaviour of the mass balance terms with temperature. Accumulation rates decrease in a colder climate and thus place an upper limit on the mass balance. Ablation rates, on the other hand, increase much faster with temperature than accumulation rates, so that there is in principle no lower limit on the mass balance. Typical time scales for build-up are of the order of a few tens of thousands of years for the colder climates, and even longer for the warmer climates. The growth curve for $+17 \mathrm{~K}$ shows how the height-mass balance feedback becomes active. In this case, the final equilibrium is not reached even after the 60000 years of simulated evolution shown on Fig. 10.

Reducing the size of an ice sheet is a much faster process, because of the higher magnitude of ablation rates. The curves displayed in Fig. 11 clearly show how the ice sheet first loses volume because of a shrinking domain, which has an immediate effect typically lasting 5000 to 10000 years, whereafter the ice sheet grows again because of the lagging effects associated with rising accumulation rates.

\section{Sensitivity Study}

When transposing these results to Tertiary environments, one should of course keep in mind that the climatic and topographical boundary conditions may have been very different from today's. For instance, the Transantarctic Mountains, which play an important role in the ice sheet's inception, may have been substantially lower. In addition, 


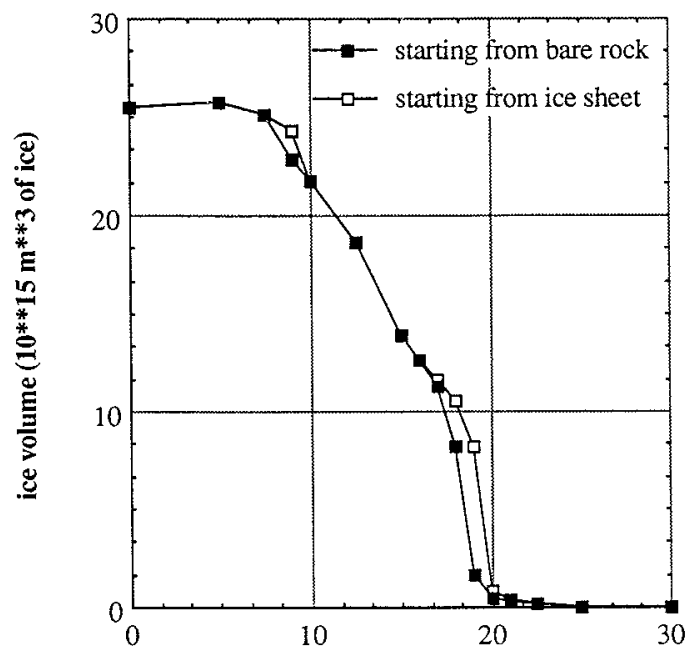

temperature rise above present level $(\mathbf{K})$

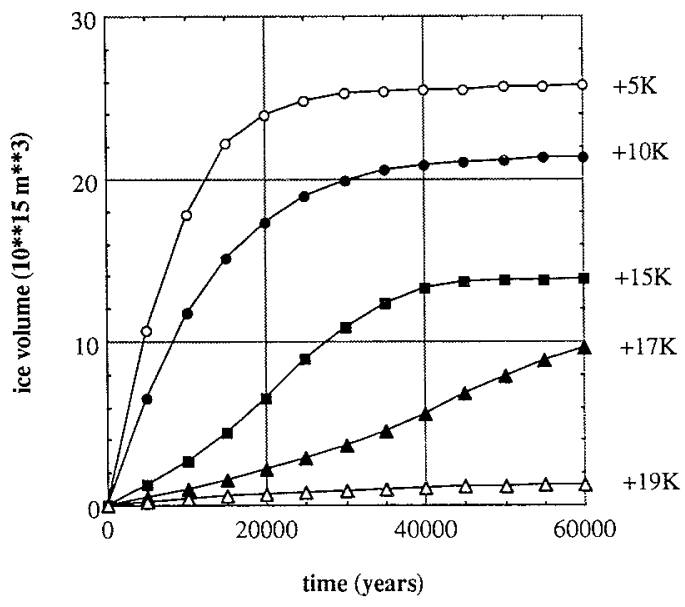

Fig. 10. Growth curves of the Antarctic Ice Sheet for various temperature changes above the present level, starting with an ice-free continent as an initial condition.

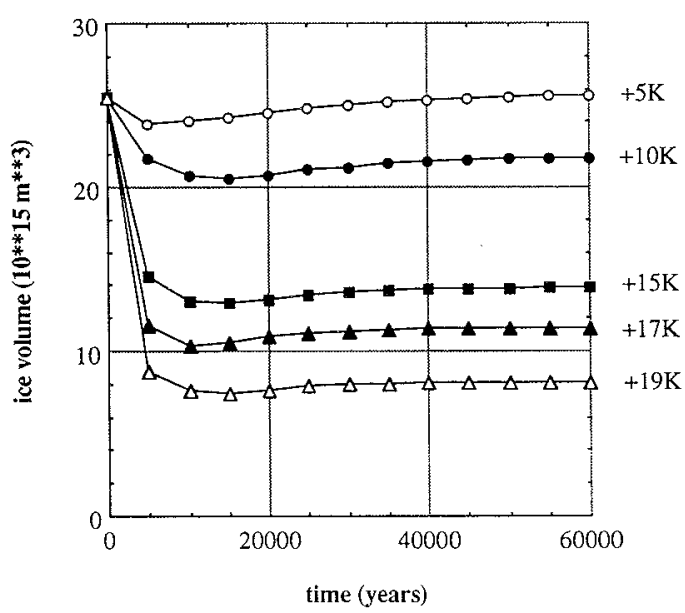

Fig. 11. Time scales for ice-sheet decay after the model has been submitted to a sudden climatic warming of the magnitude shown at the right. These experiments started with the present ice sheet as initial condition.

red by apatite fission track analysis (Fitzgerald $e t$ al. 1987) and heat flow calculations (Stern and ten Brink, 1989). Nevertheless, the evidence is sparse and it seems that present data cannot yet constrain the timing or amount of surface uplift with any precision. The uplift history is also likely to be different for each of the individual blocks that comprise the Transantarctic Mountains.

In this study, the effect of topography was tested 


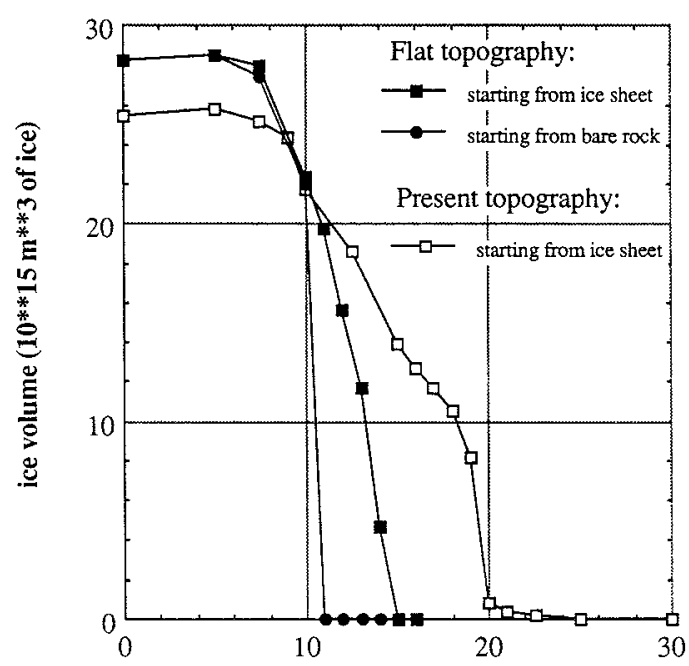

temperature rise above present level $(\mathbf{K})$

Fig. 12. Steady state ice volumes for the series of experiments in which the bedrock was flattened out and mountains removed. The curve for the experiments with the present topography is added for comparison.

under a maximum scenario. This should give an idea of what to expect when conditions are stretched to the extreme. A new dataset for topography was constructed by flattening out the unloaded bed elevations above an altitude of 100 metres. This was done by taking the square root of elevation and multiplying the result by 10 . This effectively lowered all topography to below $500-600$ metres above sea level everywhere. With this setup, simulated surface elevations over the East Antarctic Ice Sheet are typically about 3000 metres in the centre, and not surprisingly, ice sheets tend to become more circular with their summits migrating to the South Pole.

The corresponding curves of steady state ice volume versus the temperature perturbation are displayed in Fig. 12. The ice sheet on a flat bed now disappears for a temperature rise of $15 \mathrm{~K}$, which is $10 \mathrm{~K}$ less than the amount needed to melt the East Antarctic Ice Sheet for its present-day bed, but is nonetheless still a very substantial warming. It is also interesting to note that the hysteresis is much more pronounced than in the standard experiment (Fig. 9). Both curves are now separated by $5 \mathrm{~K}$ and also their gradients are much larger. This indicates that the ice sheet on a flat bed is more responsive to climatic change. The interpretation is that the ice sheet is able to oscillate between a very small and a very large ice sheet for temperatures fluctuating in the relatively small range of between +10 and $+15 \mathrm{~K}$. The lowering of the Transantarctic Mountains therefore increases the likelihood of large and rapid ice sheet changes.

\section{Mass Balance Parameters}

Little is known about late-Tertiary climatic conditions prevailing over Antarctica, in particular with respect to the relation between temperature and patterns of accumulation and surface melting, both latitudinally and seasonally. It has been suggested that $\mathrm{CO}_{2}$ levels during the Pliocene were higher than today, implying an analogy between GCM simulations for a $\mathrm{CO}_{2}$ - doubling and Pliocene warmth (Crowley, 1991), but such inferences remain very speculative. Another GCM study was conducted by Oglesby (1989), and specifically aimed at investigating the effects of closing the Drake Passage (representing an increased meridional heat transport by the ocean) and a lower continental elevation on Antarctic glaciation. This study demonstrated the difficulties involved to explain frost- and ice-free conditions over Antarctica. Under all circumstances, even with greatly increased atmospheric carbon dioxide, conditions would still have been favourable for the maintenance of an Antarctic Ice Sheet. That is, far-below-zero temperatures still exist and a positive surface mass-balance prevails, certainly in the more central areas. Of interest for the present study, however, is that summer temperature deviations may have been larger than mean annual variations because of a lower albedo over a tundra-like surface, and that surface melting rates may have been larger than those observed on Greenland today for a similar temperature.

With these suggestions in mind, a few additional sensitivity experiments were set up, in which parameters in the mass balance model were stretched to the limits suggested by the study by Oglesby (1989) so as to produce the smallest ice sheets. These additional conditions were a doubling of the degree-day factors to 0.006 and $0.016 \mathrm{my}^{-1} / \mathrm{PDD}$ for snow and ice respectively; a $50 \%$ higher temperature rise during the summer melting season than during the year; and the (not very realistic) assumption that accumulation rates do not increase in a warmer climate and remain at their present low levels. The resulting ice-volume curves are shown in Fig. 13. Again, the ice sheet disappears more readily, but still requires a climatic 


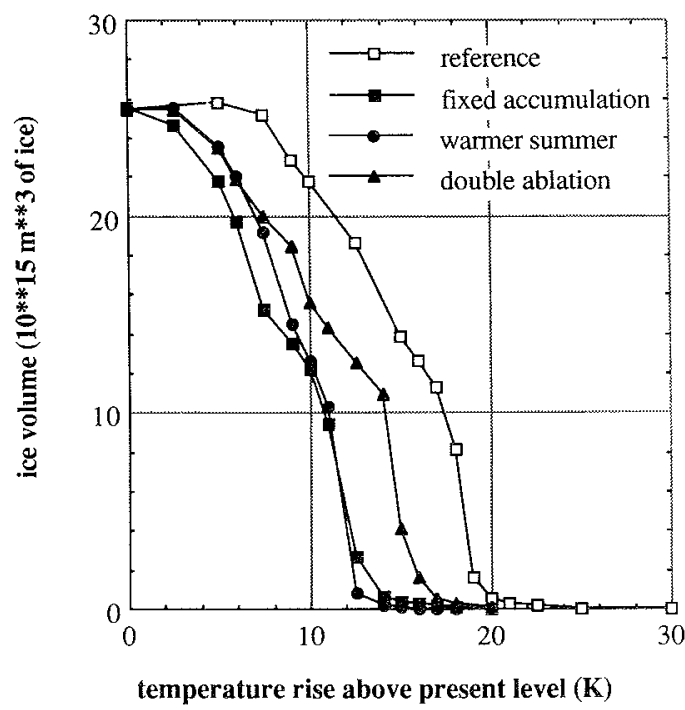

Fig. 13. Solutions for the sensitivity tests involving changes in the mass balance model. These curves are for experiments in which the initial condition was an ice-free continent after isostatic rebound.

warming in the range of +10 to $+15 \mathrm{~K}$ to become sufficiently small to expose interior basins.

\section{Another Mechanism for Episodal East Antarctic Ice Sheet Destruction?}

In view of the large warming needed to melt the ice sheet down from the surface, an important question is to know whether there are perhaps other mechanisms able to explain episodal destruction and deglaciation of East Antarctica. In this respect, several instability mechanisms have been suggested that could have played a role.

First there is marine ice sheet instability, which holds that the stability of an ice sheet grounded below sea level crucially depends on its surrounding ice shelves, which are believed to keep the grounded ice sheet in place (Mercer, 1978; Thomas and Bentley, 1978; Lingle, 1984; and many others). Any weakening of these ice shelves would under certain circumstances lead to a run-away process in which the entire marine ice sheet collapses. This mechanism received a lot of attention with regard to the West Antarctic Ice Sheet in the late 1970 s, though the effectiveness of this mechanism remains the subject of considerable debate. Later modelling work (Van der Veen, 1985; Muszynski and Birchfield, 1987), in which the entire ice sheet system-ice sheet, grounding line and ice shelf-is modelled in an integrated way does not appear to exhibit the catastrophic behaviour common to earlier work based on a study by Thomas (1977). Also all conditions required for this mechanism are not fulfilled in East Antarctica, which is only truly marine-based in a relatively small area in Wilkes and George V Land. Furthermore, the bedrock does not have the required inward-sloping topography. This virtually excludes the marine ice sheet instability mechanism as a likely candidate to explain East Antarctic Ice Sheet destruction.

Two other mechanisms, creep instability and surging, call on the thermodynamics of polar ice sheets. Clarke et al. (1977) and Schubert and Yuen (1982) have suggested that the East Antarctic Ice Sheet may exhibit creep instability because of the feedback between ice temperature and ice velocity: the warmer the ice, the more easily it deforms and the more shear heating is produced, which in turn leads to higher temperatures and so forth. Their scenario calls on climatically enhanced accumulation to increase the thickness of the East Antarctic Ice Sheet above a critical value for the onset of an explosive shear heating instability. This would cause massive melting at the base and initiate a surge. However, their instability may be a model artefact rather than a realistic feature because of the neglect of horizontal heat advection, which excludes a basic damping mechanism in the system (Huybrechts and Oerlemans, 1988).

A similar remark applies to large-scale surging (Budd and McInnes, 1979). The thermodynamics employed in these studies are rather simple and originate from glacier studies, and it is doubtful whether these could be applied to large continental ice sheets. Another critical factor in these models is the way basal sliding is treated and how it depends on the details of the basal hydraulics.

In all, these instability mechanisms are unlikely to have caused the kind of ice sheet geometries necessary to explain the waxing and waning ice sheet hypothesis. Also, these mechanisms would at best explain a periodic thinning of the ice sheet, and not necessarily the removal of large parts of the ice sheet, which would still have to result from melting down from the surface.

\section{Concluding Discussion}

According to the model results presented in this paper, the East Antarctic Ice Sheet appears to be 
very robust to a climatic warming. It would take a temperature warming of between 17 and $20 \mathrm{~K}$ to produce an ice-free corridor over the Wilkes and Pensacola basins and of between 20 and $25 \mathrm{~K}$ to completely remove the ice sheet from the interior of the continent. Moreover, for a warming of up to $5 \mathrm{~K}$, the ice sheet would be even larger than today because the increase in snowfall would outweigh the increase in surface melting. Even under the extreme conditions of a flatter bedrock and mass-balance parameters stretched to their limits, the ice sheet would still need a temperature rise of the order of 10 to $15 \mathrm{~K}$ to melt completely down.

These results have important consequences for the multi-dynamic model proposed for the lateTertiary glacial history of Antarctica. Based on these findings, there are serious climatological and glaciological difficulties associated with a Pliocene disintegration of the East Antarctic Ice Sheet. The main problem is that the only realistic mechanism able to explain a smaller ice sheet is massive surface melting, and that this requires a temperature rise well in excess of the rather modest Pliocene warmings recorded in the marine isotope records (Kennett, 1982) and other sources (Crowley, 1991). Moreover, an alternative instability mechanism is hard to find, because the prerequisite for any mechanism involving the decoupling of the ice from its base, that is, widespread basal melting, does not seem to take place in a warmer climate.

Additionally, there are problems with the proposed location for marine diatom deposition. The Wilkes and Pensacola basins are located close to the South Pole, where climatic conditions can be expected to be at their most severe, so that ice-free terrain is produced only when the East Antarctic Ice Sheet as a whole has almost entirely disappeared. But even then, these basins would quickly ( $\approx$ after a few thousands of years) rise above sea level, making a marine environment hard to conceive unless the bed had an entirely different structure.

At the other extreme, a giant ice sheet overriding the Transantarctic Mountains also has difficulties. Such a giant ice sheet necessarily presupposes the existence of a West Antarctic Ice Sheet with ice shelves that can interact with sea level, implying temperatures not too far above present levels. Moreover, for this ice sheet to expand to the margin of the continental shelf, a low global sea level would be required, perhaps indicating ice build-up on continents elsewhere, for which there is otherwise no clear evidence. Nevertheless, both these conditions, a West Antarctic Ice Sheet and a low global sea level, are associated with cold global climates, which would not produce the large precipitation amounts needed to cause massive overriding of the Transantarctic Mountains, leading to a unified ice sheet with a single dome. This makes also the giant ice sheet reconstruction difficult to understand unless the climate system operated in a completely different way.

Following these arguments, it seems that neither the extreme dwarf ice sheet nor the giant ice sheet hypothesis are a likely option during the more recent glacial history of the last 5 to 10 million years. Given the constraints on the climatic history, the model experiments presented here rather confirm the classic concept of a quasi-permanent and stable East Antarctic Ice Sheet, together with a West Antarctic Ice Sheet that accounts for the bulk of the variability. If anything, the Pliocene East Antarctic Ice Sheet is likely to have been somewhat bigger rather than smaller than today.

However, as also became clear in this study, both the removal of large parts of the East Antarctic Ice Sheet and the overriding of the Transantarctic Mountains certainly become more credible as one goes further back in time to periods with warmer climatic episodes and a less elevated topography. If the Transantarctic Mountains were indeed much lower, a less extensive and thinner East Antarctic Ice Sheet would be needed to override them. The presence of the West Antarctic Ice Sheet may not even be required, so that overriding may have been produced with temperatures substantially above present levels. It is tempting to speculate that this may also have led to the right conditions for a more dynamic ice sheet. Such a system would be much closer to the $10-15 \mathrm{~K}$ temperature rise needed for massive surface ablation at the margin. In addition, it could have produced the larger precipitation rates needed for overriding during a cooler interval, not only because of air temperature, but also because of a nearer moisture source due to a less extensive sea-ice cover and more open water around the continent. Investigating the likelihood of such a scenario would require the coupling of the ice sheet model to atmospheric circulation models and models for the development of the subglacial landscape. These combined studies have yet to be done. 


\section{Acknowledgements}

During this research, I received initial support from the Belgian Research Program on Antarctica (Science Policy Office, Services of the Prime Minister) and from the Belgian National Fund for Scientific Research (NFWO) as a postdoctoral researcher. My introduction to the geological background and its wider implications benefited greatly from discussions with George Denton, David Harwood, Jim Kennett, David Marchant, David Sugden and Peter Webb. Thanks are furthermore due to Jim Fastook, John Spletstoesser and Tony Payne for their critical reviews of the manuscript. This is contribution No. 690 of the Alfred-Wegener-Institut für Polar- und Meeresforschung.

Philippe Huybrechts, Alfred-Wegener-Institut für Polar- und Meeresforschung, Postfach 120161, D27515 Bremerhaven, Germany, and Geografisch Instituut, Vrije Universiteit Brussel, Pleinlaan 2, B1050 Brussel, Belgium.

\section{References}

Barrett, P.J., Adams, C.J., McIntosh, W.C., Swisher 11I, C.C. and Wilson, G.S., 1992: Geochronological evidence supporting Antarctic deglaciation three million years ago. Nature, $359,816-818$.

Braithwaite, R.J. and Olesen, O.B., 1989: Calculation of glacier ablation from air temperature, west Greenland. In: Oerlemans, J. (ed.). Glacier fluctuations and climatic change. Dordrecht, Kluwer Academic Publishers, $219-$ 233.

Budd,W.F. and McInnes, B.J., 1979: Periodic surging of the Antarctic Ice Sheet-an assessment by modelling. Hydrol. Sci. Bull, , 24, 95-104.

Clarke, G.K.C., Nitsan, U. and Paterson, W.S.B., 1977: Strain heating and creep instability in glaciers and ice sheets. Rev. Geophys. Space Phys., 15, 235-247.

Crowley, T.J., 1991: Modeling Pliocene warmth.Quaternary Science Reviews, 10, 275-282.

Denton, G.H., 1985: Did the Antarctic Ice Sheet influence Late Cainozoic climate and evolution in the southern hemisphere? South African Joumal of Science, 81, 224 229.

Denton, G.H., Prentice, M.L., Kellogg, D.E. and Kellogg, T.B., 1984: Late Tertiary history of the Antarctic Ice Sheet: Evidence from the Dry Valleys. Geology, 12, 263267.

Denton, G.H., Prentice, M.L. and Burckle, L.H., 1991: Cainozoic history of the Antarctic Ice Sheet. In: Tingey, R.J. (ed.). The Geology of Antarctica. Oxford, Oxford University Press, 365-433.

Drewry, D.J. (ed.), 1983: Antarctic glaciological and geophysical folio. Scott Polar Research Institute (Cambridge).

Fitzgerald, P.G., Sandiford, M., Barrett, P.J. and Gleadow, A.J.W., 1987: Asymmetric extension associated with up- lift and subsidence in the Transantaretic Mountains and Ross Embayment. Earth Planet. Sci. Letters, 81, 67-78.

Fortuin, J.P.F and Oerlemans, J., 1990: Parameterisation of the annual surface temperature and mass balance of Antarctica. Ann. Glaciol., 14, 78-84.

Giovinetto, M.B., Waters, N.M. and Bentley, C.R., 1990: Dependence of Antarctic surface mass balance on temperature, elevation, and distance to open occan. J. Geophys. Res., 95, D4, 3517-3531.

Harwood, D.M., 1986: Recycled siliceous microfossils from the Sirius Formation. Antarctic Journal of the U.S., 18,5 , $101-103$.

Huybrechts, Ph., 1990: A 3-D model for the Antarctic Ice Sheet: a sensitivity study on the glacial-interglacial contrast. Clim. Dyn., 5, 79-92.

- 1992: The Antarctic Ice Sheet and environmental change: a three-dimensional modeling study. Berichte zur Polarforschung, 99, $241 \mathrm{p}$.

-.. In press. Formation and disintegration of the Antarctic Ice Sheet. Ann. Glaciol., 20.

Huybrechts, Ph. and Oerlemans, J., 1988: Evolution of the East-Antarctic Ice Sheet: a numcrical study on thermomechanical response paterns with changing climate. Ann. Glaciol., 11, 52-59.

- 1990: Response of the Antarctic Ice Sheet to futurc greenhouse warming. Clim. Dyn., 5, 93-102.

Huybrechts, Ph., Letreguilly, A. and Reeh, N., 1991: The Greenland Ice Sheet and greenhouse warming. Palaeogeog. Palaeoclim. Palaeoecol. (Glob. Planet. Change sect.), 89, 399-412.

Jouzel, J., Raisbeck, G., Benoist, J.P., Yiou, F, Lorius, C., Raynaud, D., Petit, J.R., Barkov, N.I., Korotkevich, Y.S. and Kotlyakov V.M., 1989: A comparison of deep Antarctic cores and their implication for climate between 65000 and 15000 years ago. Quat. Res., 31, 135 150.

Kennett, J.P., 1977: Cenozoic evolution of Antarctic glaciation, the circum-Antarctic ocean and their impact on global palaeoceanography. $J$. Geophys. Res., 82, 38433860 .

1982: Marine Geology. Englewood Cliffs, Prentice-Hall.

Lingle, C.S., 1984: A numerical model of interactions between a polar ice stream and the ocean: application to icc stream E, West Antarctica. J.Geophys. Res., 89, 35243549.

Marchant, D.R., Swisher III, C.C., Lux, D.R., West, D.P. and Denton G.H., 1993: Pliocene Paleoclimate and East Antarctic Ice-Sheet History from Surficial Ash Deposits. Science, 260, 667-670.

McKelvey, B.C., Webb, P.N., Harwood, D.M. and Mabin, M.C.G., 1991: The Dominion Range Sirius group: a record of the late Pliocene-early Pleistocene Beardmorc Glacier. In: Thomson, M.R.A. et al. (eds.). Geological Evolution of Antarctica, Cambridgc, Cambridge University Press, 675-682.

Mercer, J.H., 1978: West Antarctic Ice Sheet and $\mathrm{CO}_{2}$ greenhouse effect: a threat of disaster. Nature, 271, 321325 .

Muszynski, I. and Birchfield, G.E., 1987: A coupled marine, ice stream-ice shelf model. J. Glaciol., 33, 3-15.

Oerlemans, $J ., 1981$ : Some basic experiments with a vertically-integrated ice sheet model. Tellus, 33, 1-11.

Oglesby, R.J., 1989: A GCM study of Antarctic glaciation, Clim. Dyn., 3, 135-156.

Orvig, S., 1970: World survey of Climatology, vol. 14: Climates of the polar regions. Amsterdam, Elsevier, $370 \mathrm{p}$. 
Paterson, W.S.B., 1981: The physics of glaciers $2^{\text {nd }}$ edition, Oxford, Pergamon Press, $380 \mathrm{p}$.

Reeh, N., 1989: Parameterisation of melt rate and surface temperature on the Greenland Ice Sheet. Polarforschung, 59, 113-128.

Schubert, G. and Yuen, D.A., 1982: Initiation of ice ages by creep instability and surging of the East Antarctic Ice Sheet. Nature, 296, 127-130.

Stern, T.A. and ten Brink, U.S., 1989: Flexural uplift of the Transantarctic Mountains, J.Geophys.Res., 94, 1031510330.

Sugden, D., 1992: Antarctic ice sheets at risk? Nature, 359 , $775-776$.

Thomas, R.H., 1977: Calving bay dynamics and ice sheet retreat up the St Lawrence valley system. Geogr. Phys. Quat., 31, 167-177.
Thomas, R.H. and Bentley, C.R., 1978: A model for Holocene retreat of the West Antarctic Ice Sheet. Quat. Res., 10, 150-170.

van der Veen, C.J., 1985: Response of a marine ice sheet to changes at the grounding line. Quat. Res., 24, 257-267.

Webb, P.N., D.M. Harwood, McKelvey, B.C., Mercer, J.H. and Stott, L.D., 1984: Cenozoic marine sedimentation and ice-volume variation on the East Antarctic craton. Geology, 12, 287-291.

Webb, P.N., D.M. Harwood, McKelvey, B.C., Mabin M.C.G. and Mercer, J.H., 1986: Late Cenozoic tectonic and glacial history of the Transantarctic Mountains. Ant. Journal U.S., 21, 99-100.

Webb, P.N. and Harwood, D.M., 1991: Late Cenozoic glacial history of the Ross Embayment, Antarctica. Quaternary Science Reviews, 10, 215-223. 